\title{
Mesona Chinensis Benth extract prevents AGE formation and protein oxidation against fructose-induced protein glycation in vitro
}

Sirichai Adisakwattana ${ }^{1,2^{*}}$, Thavaree Thilavech ${ }^{2,3}$ and Charoonsri Chusak ${ }^{1,2}$

\begin{abstract}
Background: Mesona chinensis Benth (Chinese Mesona), an economically significant agricultural plant, is the most widely consumed as an herbal beverage in Southeast Asia and China. The objective of this study was to evaluate the inhibitory activity of Mesona chinensis (MC) extract on the formation of advanced glycation end products (AGEs) and protein oxidation in an in vitro model of fructose-mediated protein glycation.

Methods: The content of total polyphenolic compounds was measured by using Folin-Ciocalteu assay. Antiglycation activity was determined using the formation of AGE fluorescence intensity, $N^{\varepsilon}$-(carboxymethyl)lysine (CML), the level of fructosamine, and the formation of amyloid cross $\beta$-structure. The protein oxidation was examined using the level of protein carbonyl content and thiol group.

Results: Our results revealed that the content of total polyphenolic compound in MC extract was $212.4 \pm 5.6 \mathrm{mg}$ gallic acid equivalents $/ \mathrm{g}$ dried extract. MC extract $(0.25-1.00 \mathrm{mg} / \mathrm{mL})$ significantly inhibited the formation of fluorescence AGEs in fructose-glycated bovine serum albumin (BSA) during 4 weeks of study. Furthermore, MC extract also decreased the level of $\mathrm{N}^{\varepsilon}-\mathrm{CML}$, fructosamine, and amyloid cross $\beta$-structure in fructose-glycated BSA. While the total thiol group was elevated and the protein carbonyl content was decreased in BSA incubated with fructose and $M C$ extract.
\end{abstract}

Conclusions: The extract of MC inhibits fructose-mediated protein glycation and protein oxidation. This edible plant could be a natural rich source of antiglycation agent for preventing AGE-mediated diabetic complication.

Keywords: Mesona chinensis, Protein glycation, Fructose, Advanced glycation end products

\section{Background}

Chronic hyperglycemia plays a vital role in the development of long-term diabetic complications by increasing non-enzymatic protein glycation and the gradual formation of advanced glycation end products (AGEs) in body tissues [1]. Protein glycation causes marked changes in the structural properties and stability that impair protein function associated with the pathogenesis of age-related diseases [2]. Consequently, the interaction of AGEs with receptors for AGEs (RAGE) directly activates multiple intracellular signaling, gene expression, and the secretory

\footnotetext{
* Correspondence: sirichai.a@chula.ac.th

'Department of Nutrition and Dietetics, Faculty of Allied Health Sciences,

Chulalongkorn University, Bangkok 10330, Thailand

${ }^{2}$ Research Group of Herbal Medicine for Prevention and Therapeutic of Metabolic diseases, Chulalongkorn University, Bangkok 10330, Thailand Full list of author information is available at the end of the article
}

pro-inflammatory molecules accompanied by increasing free radicals that contribute towards pathologic complications related to diabetes such as atherosclerosis, nephropathy, peripheral neuropathy, retinopathy and cataract [3]. Aminoguanidine, a prototype therapeutic agent for inhibition of AGE formation, has received the most interest from a clinical trials perspective $[4,5]$. However, it may have serious toxicity when administered for diabetic nephropathy [5]. Therefore, there is considerable interest in search of plant-based diets with antiglycation activity as they may potentially inhibit AGE formation resulting in delaying and preventing the onset of diabetic complications with minimal side effects [6-8].

Many studies have shown the beneficial effect of plantbased diets for the inhibition of protein glycation in vitro and in vivo $[9,10]$. Mesona chinensis Benth (Chinese 
Mesona), belonging to the Lamiaceae family, is an economically important agricultural plant in Southeast Asia and China [11]. This plant-based diet is the most widely consumed as an herbal beverage and a gelatin-type dessert (Grass jelly). In addition, it has been utilized in ancient folk medicine for treatment of hypertension, diabetes, and liver diseases [10]. The assessment of available nutrient status has shown that $M$. chinensis (MC) includes 17 amino acids (7 essential amino acids), carbohydrate, fat, fiber, polyphenols, and flavonoids $[12,13]$. However, there were no reports in the scientific literature on antiglycation activity of MC. Hence, the aim of this study were carried out to investigate the inhibitory effects of $M C$ against fructose-mediated non-enzymatic glycation and oxidationdependent damages to BSA. These results reported herein support the notion that this plant-based diet could be a new avenue for treatment and prevention of protein glycation and related diseases conditions.

\section{Methods}

Chemicals

Bovine serum albumin (BSA, fraction V), aminoguanidine hydrochloride (AG), nitroblue tetrazolium (NBT), 1-deoxy1-morpholino-D-fructose (1-DMF), guanidine hydrochloride, congo red, 5,5'-dithiobis(2-nitrobenzoic acid) (DTNB) and L-cysteine were purchased from Sigma-Aldrich Co. (St. Louis, MO, USA). D-fructose and 2,4-dinitrophenyl hydrazine (DNPH) were purchased from Ajax Finechem (Taren Point, Australia). Trichloroacetic acid (TCA) was purchased from Merck (Darmstadt, FR, Germany). OxiSelect ${ }^{\mathrm{TM}} \mathrm{N}^{\varepsilon}$-(carboxymethyl) lysine (CML) ELISA kit was obtained from Cell Biolabs (San Diego, CA, USA). All other chemicals and solvents used in this study were of analytical grade.

\section{Plant preparation and extraction}

The dried whole plants were purchased from a specific herbal drugstore, Bangkok, Thailand. The plant has been authenticated at the Professor Kasin Suvatabhandhu Herbarium, Department of Botany, Chulalongkorn University, Thailand, Voucher specimen: A013637 (BCU). The dried plants (300 g) were boiled in distilled water $(4 \mathrm{~L})$ at $90^{\circ} \mathrm{C}$ for 4 hours. After boiling, the residue of plant was filtered with a colander. The aqueous extraction was dried using a spray dryer SD-100 (Eyela world, Tokyo Rikakikai Co., LTD, Japan). The condition of spray dryer was inlet temperature $178-180^{\circ} \mathrm{C}$, outlet temperature $85-95^{\circ} \mathrm{C}$, blower $(0.80-0.90) \mathrm{m}^{3} / \mathrm{min}$, and atomizing at $90 \mathrm{kPa}$. The powder extract was kept in a dry place.

\section{Measurement of total polyphenolic content}

The content of total polyphenolic compounds in the extract was determined using the Folin-Ciocalteu's phenol reagent [14]. The content of total polyphenolic compounds was expressed as mg gallic acid equivalents/g dried extract.

\section{In vitro glycation of bovine serum albumin}

Glycated BSA was done according to a previously published method [15]. Briefly, $10 \mathrm{mg} / \mathrm{mL}$ BSA $(0.50 \mathrm{~mL})$ was incubated with $0.46 \mathrm{~mL}$ of $500 \mathrm{mM}$ fructose in $100 \mathrm{mM}$ phosphate buffered-saline ( $\mathrm{pH}$ 7.4) containing $0.02 \%$ sodium azide at $37^{\circ} \mathrm{C}$ for 4 weeks. Before incubation, $0.04 \mathrm{~mL}$ of $\mathrm{MC}$ extract (final concentration: 0.25 $1.00 \mathrm{mg} / \mathrm{mL}$ ) and AG (final concentration: $1.00 \mathrm{mg} / \mathrm{mL}$ ) were added into the reaction mixtures. The formation of fluorescent AGEs was measured by using a spectrofluorometer. The fluorescent intensity was measured at an excitation wavelength of $355 \mathrm{~nm}$ and emission wavelength of $460 \mathrm{~nm}$. The percentage of fluorescent AGE formation was calculated as follows:

$$
\begin{aligned}
& \text { Inhibition of fluorescent AGEs (\%) } \\
& \qquad=\left[\left(F_{C}-F_{C B}\right)-\left(F_{S}-F_{S B}\right) /\left(F_{C}-F_{C B}\right)\right] x 100
\end{aligned}
$$

Where $\mathrm{F}_{\mathrm{C}}$ and $\mathrm{F}_{\mathrm{CB}}$ were the fluorescent intensity of control with fructose and blank of control without fructose, $F_{S}$ and $F_{S B}$ were the fluorescent intensity of sample with fructose and blank of sample without fructose.

The concentration of non-fluorescent AGEs $\left(\mathrm{N}^{\varepsilon}\right.$ (carboxymethyl) lysine, CML), a major non-fluorescent AGEs structure, was measured by using enzyme linked immunosorbant assay (ELISA) kit according to the manufacturer's protocol. The concentration of $\mathrm{N}^{\varepsilon}-\mathrm{CML}$ was calculated by using a standard curve of $\mathrm{N}^{\varepsilon}$-CML-BSA.

\section{Determination of fructosamine}

The level of fructosamine was measured by using nitrobluetetrazolium (NBT) dye according to a previous published method [16]. Briefly, glycated BSA $(10 \mu \mathrm{L})$ was incubated with $0.5 \mathrm{mM}$ NBT $(90 \mu \mathrm{L})$ in $100 \mathrm{mM}$ carbonate buffer, $\mathrm{pH} 10.4$ at $37^{\circ} \mathrm{C}$. The absorbance was recorded at $530 \mathrm{~nm}$. The level of fructosamine was calculated by using the different absorption at the time point of 10 and $15 \mathrm{~min}$. The level of fructosamine was calculated from a standard curve (0.31-5.0 mM) prepared using 1-deoxy-1-morpholinofructose (1-DMF).

\section{Determination of protein aggregation}

Amyloid cross $\beta$-structure, a common marker for protein aggregation was measured by using a congo red assay according to a previous published method with minor modifications [17]. Briefly, the glycated BSA $(50 \mu \mathrm{L})$ was incubated with $50 \mu \mathrm{L}$ of $100 \mu \mathrm{M}$ congo red in $10 \%(\mathrm{v} / \mathrm{v})$ ethanol/PBS for $20 \mathrm{~min}$ at $25^{\circ} \mathrm{C}$. The absorbance was measured at $530 \mathrm{~nm}$. 


\section{Determination of protein thiol groups}

Protein thiol groups were measured according to a previous published method with minor modifications [18]. In brief, glycated BSA $(10 \mu \mathrm{L})$ was reacted with $90 \mu \mathrm{L}$ of $5 \mathrm{mM}$ 5,5'-dithiobis(2-nitrobenzoic acid) (DTNB) in $100 \mathrm{mM}$ phosphate buffered-saline ( $\mathrm{pH}$ 7.4) at room temperature for $15 \mathrm{~min}$. Thereafter, the absorbance was measured at $412 \mathrm{~nm}$. The level of protein thiol groups was calculated from a standard curve $(0.015-0.50 \mathrm{mM})$ prepared using L-cysteine. The results were expressed as nmol L-cysteine/mg protein.

\section{Determination of protein carbonyl contents}

The protein carbonyl contents were measured according to a previous published method with minor modifications [18]. In brief, glycated BSA $(0.10 \mathrm{~mL})$ was incubated with $0.40 \mathrm{~mL}$ of $10 \mathrm{mM}$ 2,4-dinitrophenylhydrazine (DNPH) in $2.5 \mathrm{M} \mathrm{HCl}$ at room temperature for $60 \mathrm{~min}$. Subsequently, glycated BSA was precipitated by $0.50 \mathrm{~mL}$ of $20 \%$ (w/v) trichloroacetic acid (TCA), left on ice for $5 \mathrm{~min}$, and centrifuged at $10,000 \mathrm{~g}$ at $4^{\circ} \mathrm{C}$ for $10 \mathrm{~min}$. The pellet was washed three times using 1:1 (v/v) ethanol:ethyl acetate mixture $(1 \mathrm{~mL})$. The final pellet was dissolved in $6 \mathrm{M}$ guanidine hydrochloride $(0.25 \mathrm{~mL})$. The absorbance was recorded at $370 \mathrm{~nm}$. The level of protein carbonyl contents was calculated by using an absorption coefficient of 22,000 $\mathrm{M}^{-1} \mathrm{~cm}^{-1}$. The results were expressed as $\mathrm{nmol}$ carbonyls/mg protein.

\section{Statistical analysis}

Data were expressed as mean \pm standard error of mean (SEM) $(n=3)$. The statistical significance of the results was evaluated by using one-way ANOVA. The Tukey's HSD test was used to analyze the statistically significant differences of mean. $P<0.05$ was considered to be statistically significant.

\section{Results}

Phytochemical analysis of MC extract

The present data showed that the total polyphenolic content of MC extract was $212.4 \pm 5.6 \mathrm{mg}$ gallic acid equivalents/g dried extract.

\section{The effects of MC extract on the formation of fluorescence AGEs and $\mathrm{N}^{\varepsilon}$-CML}

As shown in Figure 1, the formation of AGEs was observed weekly by the measurement of increasing fluorescent intensity in fructose-glycated BSA. The significant increase in fluorescent intensity in BSA incubated with fructose was seen during 4 weeks of the incubation. The results demonstrated that addition of MC extract $(0.25-1.00 \mathrm{mg} / \mathrm{mL})$ into the solution significantly reduced the formation of fluorescent AGE in a concentration-dependent manner throughout the study period. Similar to the effect of MC $(1.00 \mathrm{mg} /$ $\mathrm{mL}$ ), a significant inhibition of fluorescent AGEs was observed in fructose-glycated BSA plus AG $(1.00 \mathrm{mg} / \mathrm{mL})$. The percentage inhibition of MC $(0.25-1.00 \mathrm{mg} / \mathrm{mL})$ is shown in Table 1 . At week 4 of incubation, the percentage inhibition of MC extract $(0.25-1.00 \mathrm{mg} / \mathrm{mL})$ was approximately $39.60-59.42 \%$, whereas AG $(1.00 \mathrm{mg} / \mathrm{mL})$ decreased the formation of fluorescence AGEs by $90.84 \%$. The results indicated that MC extract had 1.5-times less potency than AG.

The levels of $\mathrm{N}^{\varepsilon}$-CML, a biomarker for the formation of non-fluorescent AGE are shown in Figure 2. According to the results, $\mathrm{MC}$ extract $(1.00 \mathrm{mg} / \mathrm{mL})$ and $\mathrm{AG}$ $(1.00 \mathrm{mg} / \mathrm{mL})$ decreased $26.0 \%$ and $59.7 \%$ of $\mathrm{N}^{\varepsilon}$-CML

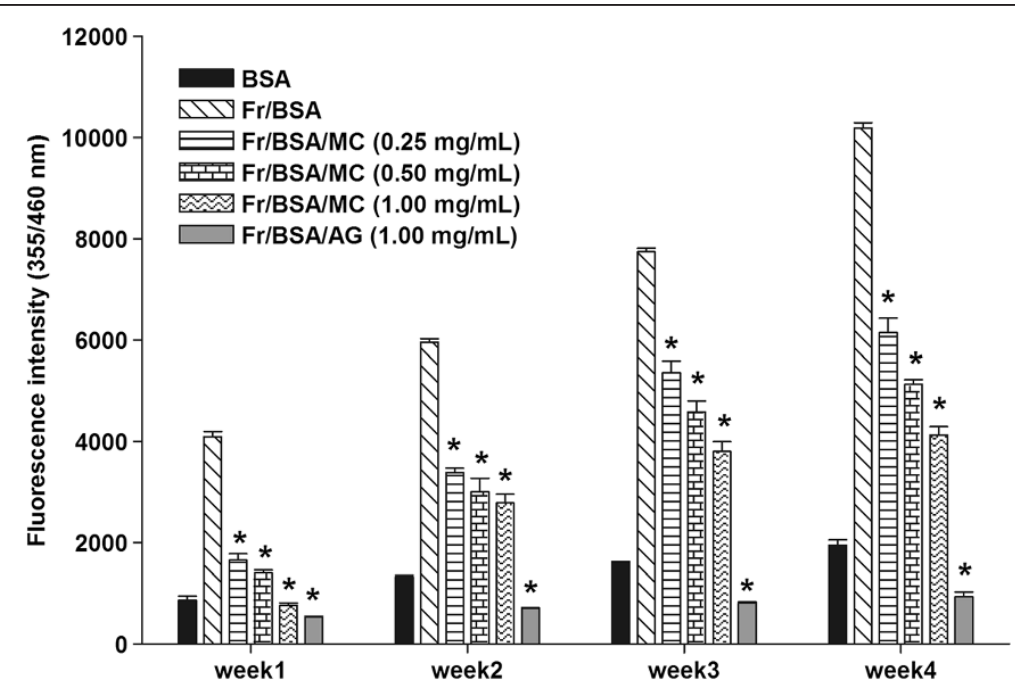

Figure 1 The effects of MC extract on the formation of fluorescent AGEs in BSA incubated with fructose. Each value represents the mean $\pm \operatorname{SEM}(n=3)$. ${ }^{*} P<0.05$ when compared to BSA/fructose at the same week. 
Table 1 The percentage inhibition of MC extract on the formation of fluorescent AGEs during the experimental period

\begin{tabular}{lllll}
\hline \multicolumn{5}{c}{ Samples \% Inhibition } \\
\hline & Week 1 & Week 2 & Week 3 & Week 4 \\
$\mathrm{Fr} / \mathrm{BSA} / \mathrm{MC}$ & $59.65 \pm 3.22$ & $43.14 \pm 1.66$ & $30.78 \pm 3.01$ & $39.60 \pm 2.96$ \\
$0.25 \mathrm{mg} / \mathrm{mL}$ & & & & \\
$\mathrm{Fr} / \mathrm{BSA} / \mathrm{MC}$ & $65.80 \pm 1.27$ & $49.44 \pm 5.04$ & $40.81 \pm 2.39$ & $49.61 \pm 1.18$ \\
$0.50 \mathrm{mg} / \mathrm{mL}$ & & & & \\
$\mathrm{Fr} / \mathrm{BSA} / \mathrm{MC}$ & $81.39 \pm 1.23$ & $53.43 \pm 2.40$ & $50.83 \pm 2.85$ & $59.42 \pm 1.78$ \\
$1.00 \mathrm{mg} / \mathrm{mL}$ & & & & \\
$\mathrm{Fr} / \mathrm{BSA} / \mathrm{AG}$ & $86.81 \pm 0.36$ & $88.27 \pm 0.35$ & $89.51 \pm 0.27$ & $90.84 \pm 0.88$ \\
$1.00 \mathrm{mg} / \mathrm{mL}$ & & & & \\
\hline
\end{tabular}

Data are expressed as mean \pm SEM, $n=3$ (Fr: fructose; MC: Mesona chinensis; AG: aminoguanidine).

formation as compared to fructose-glycated BSA, suggesting that MC extract had 2.3-times less potency than AG.

\section{The effects of MC extract on the level of fructosamine}

The effects of $\mathrm{MC}$ extract on the level of fructosamine are presented in Figure 3. The level of fructosamine in fructose-glycated BSA markedly increased throughout 4 weeks of the experiment. The increasing level of fructosamine was attenuated by $\mathrm{MC}$ extract during 4 weeks of study. In comparison at the end of study, the percentage inhibition of $\mathrm{MC}$ extract $(0.25-1.00 \mathrm{mg} / \mathrm{mL})$ was approximately 58.6-63.3\%, whereas AG $(1.00 \mathrm{mg} / \mathrm{mL}$ decreased the level of fructosamine by $40.6 \%$.

The effects of MC extract on the level of amyloid cross- $\beta$ structure

Congo red assay is generally used to measure the amount of a protein modification called amyloid cross- $\beta$ structure in glycated BSA. As shown in Figure 4, BSA incubated with fructose elevated the level of amyloid cross- $\beta$ conformation throughout 4 weeks of experimental period. In the meanwhile, fructose-glycated BSA incubated with MC extract $(0.25-1.00 \mathrm{mg} / \mathrm{mL})$ significantly attenuated an increase in the level of amyloid cross- $\beta$ structure. At 4 week of incubation, $\mathrm{MC}$ extract at concentrations of 0.25 $1.00 \mathrm{mg} / \mathrm{mL}$ reduced the level of amyloid cross- $\beta$ structure in a concentration-dependent manner (8.1\%, 9.7\% and $10.3 \%)$ Similarly, a significant decrease in the level of amyloid cross- $\beta$ structure (10.1\%) was observed in the presence of AG ( $1 \mathrm{mg} / \mathrm{mL})$ at week 4 of incubation.

\section{The effects of MC on protein oxidation}

In order to access the protein oxidation mediated by glycation process, the level of carbonyl content and thiol groups was used for determination. As shown in Figure 5, the carbonyl content of fructose-glycated BSA was significantly increased during the experimental period, whereas MC extract $(0.25-1.00 \mathrm{mg} / \mathrm{mL})$ significantly suppressed an increase in protein carbonyl content of fructoseglycated BSA. When comparing with fructose-glycated BSA at week 4 , the percentage reduction of carbonyl content by $\mathrm{MC}$ extract $(0.50-1.00 \mathrm{mg} / \mathrm{mL})$ ranged from 36.2 to $46.7 \%$. A significant reduction of protein carbonyl content $(24.4 \%)$ was seen in the presence of AG $(1 \mathrm{mg} / \mathrm{mL})$ at the same week.

The effects of MC extract on the oxidation of protein thiols are presented in Figure 6. When BSA was incubated with fructose, the level of thiol groups had continuously declined throughout the experimental period. Interestingly, there was a significant increase in the level of thiol groups after addition of $\mathrm{MC}$ extract $(0.25-1.00 \mathrm{mg} / \mathrm{mL})$ as well as AG $(1.00 \mathrm{mg} / \mathrm{mL})$. The findings showed that the

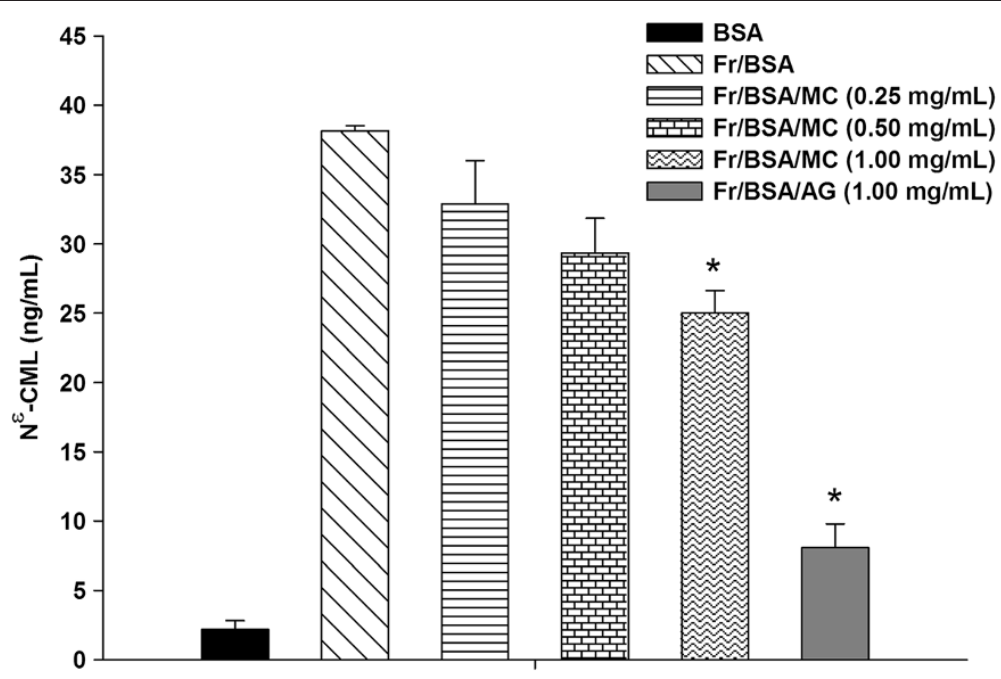

Figure 2 The effects of MC extract on the level of $\mathrm{N}^{\varepsilon}$-(carboxymethyl) lysine (CML) in BSA incubated with fructose after 4 weeks of incubation. Each value represents the mean $\pm \operatorname{SEM}(n=3) .{ }^{*} P<0.05$ when compared to BSA/fructose. 


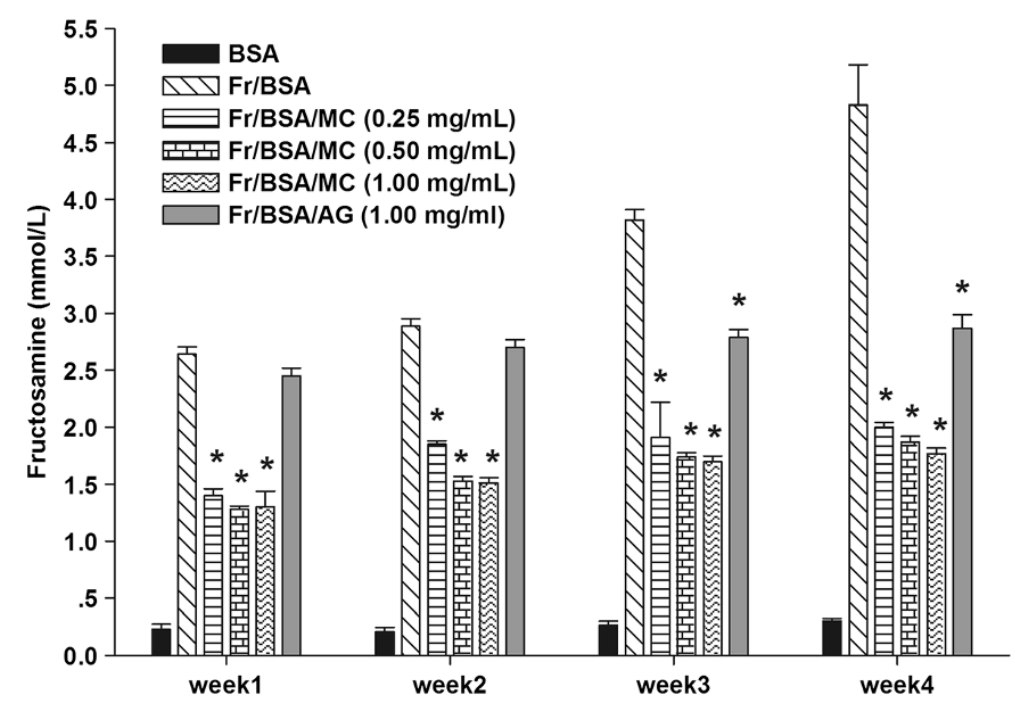

Figure 3 The effects of MC extract on the level of fructosamine in BSA incubated with fructose. Each value represents the mean \pm SEM $(n=3) .{ }^{*} P<0.05$ when compared to BSA/fructose at the same week.

percentage prevention of thiol group by $\mathrm{MC}$ ranged from 46.2 to $64.1 \%$, whereas AG (1 mg/mL) significantly prevented $(57.9 \%)$ the depletion of protein thiol groups at the week 4 of incubation. According to the results, MC extract is more potent in the reduction of fructose-induced protein oxidation than AG.

\section{Discussion}

Glycated proteins are commonly formed by a nonenzymatic reaction between the interaction of reducing sugars (fructose and glucose) and amino group of protein through a nucleophilic addition with formation of Schiff bases [1]. The unstable Schiff bases further rearrange to produce the formation of reversible Amadori products (such as fructosamine). Subsequently, the Amadori products further form cross-linked structures termed AGEs which can be classified into two major groups: fluorescent and crosslinking structures (pentosidine, crosslines, and imidazolones) and non-fluorescent and non-crosslinking structures $\left(\mathrm{N}^{\varepsilon}-\mathrm{CML}\right)$. The formation of AGEs occurs through multiple processes related in the part to generate reactive oxygen species (ROS). It is noteworthy that the superoxide anion productions (1,2- and 2,3-enolization of the Schiff's base and oxidation of the enolate anion) are particularly generated from early glycation products $[19,20]$. Consequently, reactive oxygen species-mediated

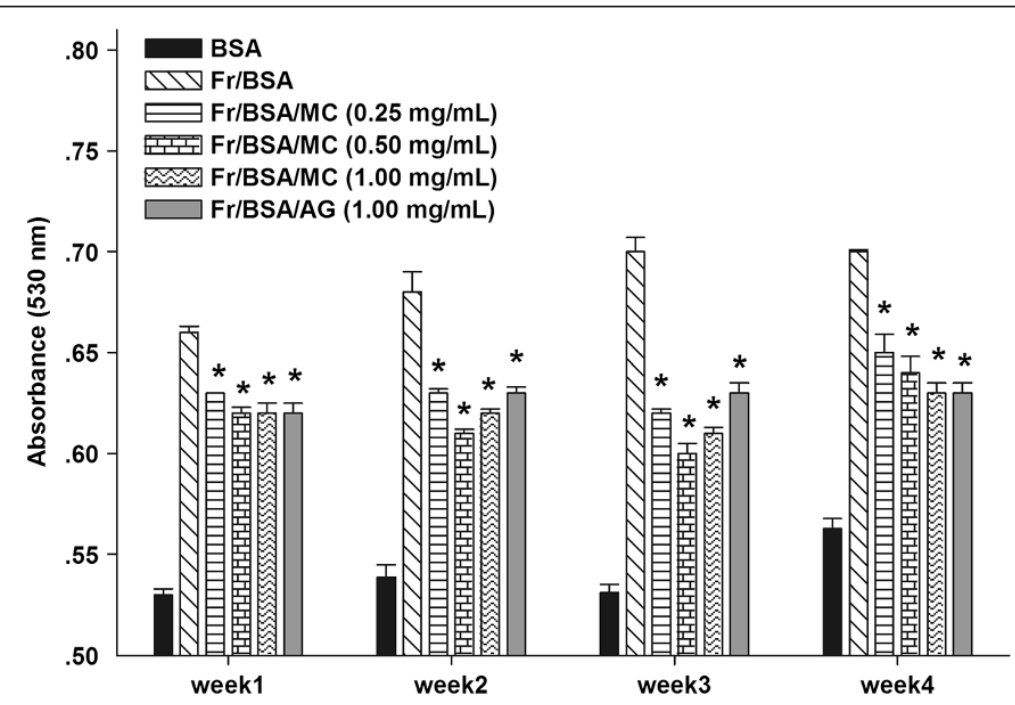

Figure 4 The effects of MC extract on the formation of amyloid cross- $\beta$ structure in BSA incubated with fructose. Each value represents the mean $\pm \operatorname{SEM}(n=3) .{ }^{*} P<0.05$ when compared to BSA/fructose at the same week. 


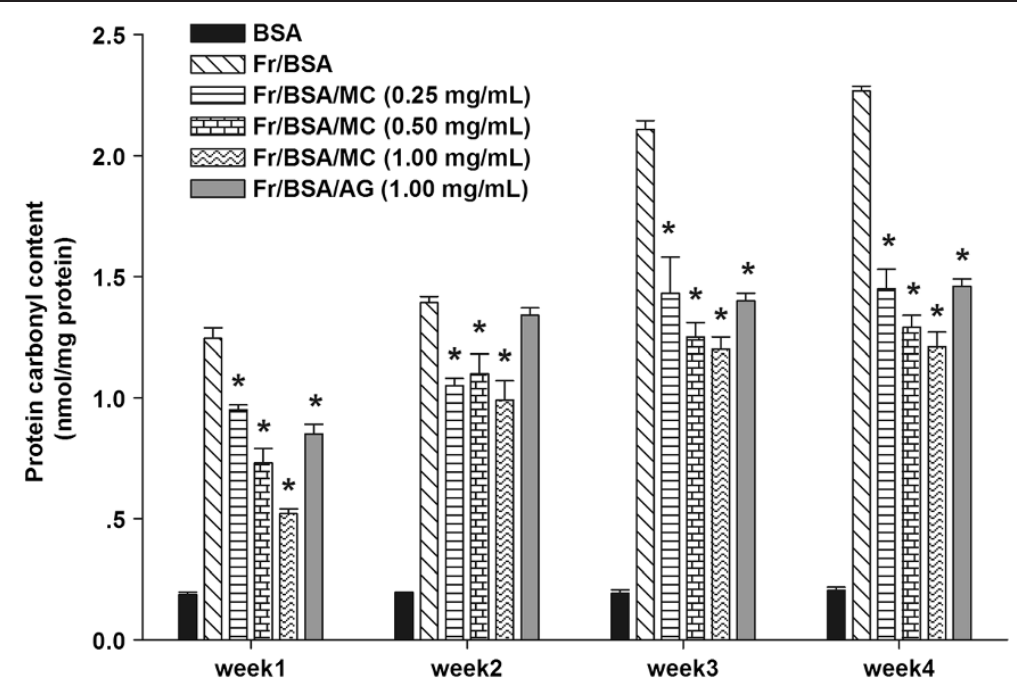

Figure 5 The effects of MC extract on the protein carbonyl content in BSA incubated with fructose. Each value represents the mean \pm SEM $(n=3)$. ${ }^{*} P<0.05$ when compared to BSA/fructose at the same week.

reactions cause the structural fragmentation to create the short-chain carbohydrate intermediates, which then alters sequentially with lysine and arginine residues to produce AGEs [19,20]. Currently, the possible anti-glycation mechanisms have been proposed such as breaking the crosslinking structures in the formed AGEs, blocking the carbonyl or dicarbonyl groups in reducing sugars, Schiff bases or Amadori products, and inhibiting the formation of late-stage Amadori products [21]. It has revealed that aminoguanidine acts as a carbonyl trapping agent by forming guanidine-dicarbonyl adducts, thereby reducing the numbers of free carbonyl groups in reducing sugars during the early stages of glycation $[21,22]$.
There has been research into the role of dietary fructose in the development of diabetes complications. Excessive fructose consumption has been linked to the development of metabolic syndromes and obesity [23]. It is well documented that long-term fructose consumption leads to glycoxidation and generation of ROS causing oxidative damage and cellular dysfunction that accompany the aging process [24]. The concentration of fructose in human tissues and fluids is generally much lower than that of glucose. Under hyperglycemic conditions, fructose can be synthesized by oxidation of sorbitol through a reaction catalyzed by polyol dehydrogenase. Ocular lens are one of specific organs where the sorbitol pathway is active,

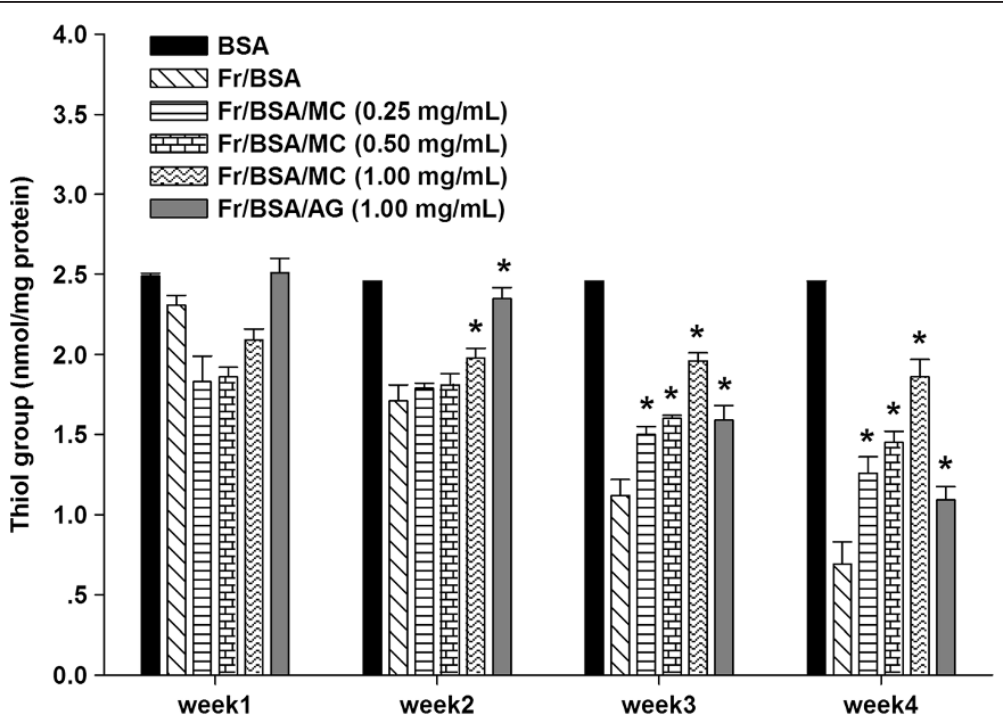

Figure 6 The effects of MC extract on the level of thiol group in BSA incubated with fructose. Each value represents the mean \pm SEM $(\mathrm{n}=3) .{ }^{*} P<0.05$ when compared to BSA/fructose at the same week. 
fructose accumulates to levels higher than in blood circulation. These results lead to accelerate the reaction between fructose and protein, giving AGE formation and accumulation in len proteins. From previous studies comparing the reactivity of glucose and fructose with proteins at physiological temperature and the equal concentration, a faster accumulation of protein-bound fluorescence and cross-linking products was from fructose $[18,25]$. In addition, fructose has been shown to be more rapidly produced dicarbonyl compounds and hydroxyl radicals by autoxidation, compared to glucose [26]. Currently, a study has been published on the site specificity of modification of lysine residues and total of $\mathrm{N}^{\varepsilon}$-CML in BSA incubated with fructose and glucose. The major site of modification by fructose, like glucose, is Lysine-524 and 31 and $76 \%$ loss of the corresponding unmodified tryptic peptide is observed at Gln525-Lys533 [22]. The fructose-modified BSA has the yield of $\mathrm{N}^{\varepsilon}$-CML being up to 17 -fold higher than glucosemodified BSA.

In a present study, we investigated the influence of MC extract on the formation of total AGEs. The results showed that MC extract efficiently inhibited fluorescent and non-fluorescent AGE formation. Furthermore, it also reduced the level of fructosamine and amyloid cross $\beta$ structure in fructose-glycated BSA. A significant increase of protein carbonyl content and oxidation of thiols in BSA were seen when the protein was glycated by fructose. When MC extract was added to the same systems, it significantly suppressed these processes. Our findings indicate that MC extract has high content of polyphenolic compounds. Several major mechanisms by which polyphenols block the carbonyl group in reducing sugars and break the crosslinking structure in the formed AGEs have recently been proposed for antiglycation activity [21]. The reduction of free radical generation by antioxidant activity of polyphenols may highlight other mechanisms for the prevention of AGE formation [21]. Recent studies carried out over the past few years have shown that polyphenolic compounds from the edible plants may play a protective role against monosaccharideinduced protein glycation $[27,28]$. The earlier studies report a strong correlation between the polyphenolic content in the tested plant extracts and the ability to inhibit protein glycation $[29,30]$. Our previous studies have previously shown the inhibitory activity on edible plant extracts containing polyphenolic compounds $[7,31]$. According to the results obtained, we addressed the hypothesis that polyphenolic compounds in the extract may be a major contributor to inhibit the formation of AGEs. However, certain active biological constituents of $\mathrm{MC}$ extract remain unknown. To prove this hypothesis, separation and characterization of polyphenolic compound in MC extract using HPLC-MS are required for further study.
In general, protein glycation can directly affect the formation of protein aggregation. The insoluble aggregates can form amyloid cross $\beta$-structure leading to alter protein structure and stability [17]. The long-term accumulation of amyloid cross $\beta$-structures in the tissues may cause the progression of pancreatic islet amyloidosis which directly destroys $\beta$-cell and impairs insulin secretion [32]. The present findings demonstrate that $\mathrm{MC}$ extract reduces the formation of amyloid cross $\beta$-structures in BSA in vitro. This beneficial effect might help reduce the risk of developing diabetes complications.

Glycation with fructose rapidly induces protein oxidation and consequently alters the structure of BSA associated with modifications of its biological properties. In particular, the thiol group of Cys residues is particularly prone to oxidative attack by free radical damage to proteins, as it is known that the formation of disulfide bonds occurs in protein aggregation and results in the loss of enzymatic activity [33]. The direct oxidation of amino acid (Lys, Arg, Thr) or secondary reaction of amino acid residues (Cys and His) with reactive carbonyl compounds can produce the formation of protein carbonyl derivatives [34]. Our findings are consistent with previous literatures indicating that fructose-induced glycation increased protein oxidation as evidenced by decreased thiol group and increased protein carbonyl content [16]. The present findings suggest that the $\mathrm{MC}$ has shown remarkable potential in protecting the protein thiols and reducing the protein carbonyl content. There is a well-documented evidence for antioxidant activity of Mesona procumbens Hemsley (Hsian-tsao), the same genus of $M$. chinensis [35]. The crude extract of $M$. procumbens leaf gum has also shown a remarkably high scavenging activity toward chemically generated reactive oxygen species [36]. Recent studies in our findings have shown the antioxidant activity of MC extract tested by different methods [37]. The findings indicated that MC extract had 7-times less potency than ascorbic acid. On the DPPH assay, MC extract had 7-times less potency than ascorbic acid. In the meanwhile, MC extract had 3-times and 3.6-times less potency of hydroxyl and superoxide radical scavenging activity than trolox, respectively. According to the abovementioned antiglycation mechanisms, MC extract may inhibit AGE formation by scavenging free radicals formed in vitro by auto-oxidation of sugars and/or oxidative degradation of Amadori products. Most antiglycation agents with antioxidant activity from the edible plants have been reported to possess polyphenolic compounds $[21,28]$. It has revealed that the inhibitory activity of polyphenols against protein glycation was strongly related to their scavenging effect on free radicals derived from the glycoxidation process [38]. According to many supporting documents, it can be assumed that polyphenolic compounds in MC extract may contribute to the antioxidant activity and antiglycation. 


\section{Conclusion}

MC extract has potent inhibitory effects on fructoseinduced protein glycation and oxidation damage in BSA. MC extract with high antiglycation activity may offer remarkable prospects for the preventive treatment of AGE-mediated diabetic complications. For these reasons, further studies should focus on the outcome of investigating effects in animal models.

\section{Abbreviations}

AGEs: Advanced glycation end products; $N^{\varepsilon}-C M L: N^{\varepsilon}$-(carboxymethyl) lysine; BSA: Bovine serum albumin; AG: Aminoguanidine; MC: Mesona chinensis.

\section{Competing interests}

The authors declare that they have no competing interests.

\section{Authors' contributions}

SA was responsible for conception and design, drafted the manuscript and revised it critically for important intellectual content. $\Pi T$ and $C C$ conducted the experiments, organized the data analysis, and interpretation of data. All authors contributed to the drafting of the manuscript and agreed on the final version of the manuscript.

\section{Acknowledgements}

We wish to thank Amway Thailand for partially financial support (Amway for Nutrition Research Grant). The authors would also like to thank Special Task Force for Activating Research (STAR) under 100 years Chulalongkorn University Fund and the Research Group of Herbal Medicine for Prevention and Therapeutic of Metabolic diseases for financial support.

\section{Author details}

'Department of Nutrition and Dietetics, Faculty of Allied Health Sciences, Chulalongkorn University, Bangkok 10330, Thailand. ${ }^{2}$ Research Group of Herbal Medicine for Prevention and Therapeutic of Metabolic diseases, Chulalongkorn University, Bangkok 10330, Thailand. ${ }^{3}$ Program in Biomedical Sciences, Graduate School, Chulalongkorn University, Bangkok 10330, Thailand.

Received: 14 October 2013 Accepted: 31 March 2014

Published: 7 April 2014

\section{References}

1. Rondeau P, Bourdon E: The glycation of albumin: structural and functional impacts. Biochimie 2011, 93:645-658.

2. Ahmed N: Advanced glycation end products-role in pathology of diabetic complications. Diabetes Res Clin Pract 2005, 67:3-21.

3. Bierhaus A, Humpert PM, Morcos M, Wendt T, Chavakis T, Arnold B, Stern DM, Nawroth PP: Understanding RAGE, the receptor for advanced glycation end products. J Mol Med 2005, 83:876-886.

4. Freedman BI, Wuerth JP, Cartwright K, Bain RP, Dippe S, Hershon K, Mooradian AD, Spinowitz BS: Design and baseline characteristics for the aminoguanidine Clinical Trial in Overt Type 2 Diabetic Nephropathy (ACTION II). Control Clin Trials 1999, 20:493-510.

5. Bolton WK, Cattran DC, Williams ME, Adler SG, Appel GB, Cartwright K, Foiles PG, Freedman BI, Raskin P, Ratner RE, Spinowitz BS, Whittier FC, Wuerth JP, ACTION I Investigator Group: Randomized trial of an inhibitor of formation of advanced glycation end products in diabetic nephropathy. Am J Nephrol 2004, 24:32-40.

6. Dearlove RP, Greenspan P, Hartle DK, Swanson RB, Hargrove JL: Inhibition of protein glycation by extracts of culinary herbs and spices. J Med Food 2008, 11:275-281.

7. Jariyapamornkoon N, Yibchok-anun S, Adisakwattana S: Inhibition of advanced glycation end products by red grape skin extract and its antioxidant activity. BMC Complement Altern Med 2013, 13:171.

8. Adisakwattana S, Jiphimai P, Prutanopajai P, Chanathong B, Sapwarobol S, Ariyapitipan $\mathrm{T}$ : Evaluation of a-glucosidase, $\mathrm{a}$-amylase and protein glycation inhibitory activities of edible plants. Int J Food Sci Nutr 2010, 61:295-305.
9. Saraswat M, Reddy PY, Muthenna P, Reddy GB: Prevention of non-enzymic glycation of proteins by dietary agents: prospects for alleviating diabetic complications. Br J Nutr 2009, 101:1714-1721.

10. Šebeková K, Somoza V: Dietary advanced glycation endproducts (AGEs) and their health effects-PRO. Mol Nutr Food Res 2007, 51:1079-1084.

11. Feng T, Gu ZB, Jin ZY: The research advances of the Mesona blume gum. China Food Addit 2005, 6:004.

12. Hailan $\mathrm{S}$, Yingzhen $\mathrm{H}$, Jingying $\mathrm{C}$ : Comparative analysis of amino acids content in Mesona chinensis from different producing areas. Chinese Wild Plant Resour 2011, 5:19.

13. Yuanping Z: Determination of total flavonoids in Mesona Chinensis by spectrophotometry. Acad Peri Farm Prod Process 2009, 6:33.

14. Mäkynen K, Jitsaardkul S, Tachasamran P, Sakai N, Puranachoti S, Nirojsinlapachai N, Chattapat V, Caengprasath N, Ngamukote S, Adisakwattana S: Cultivar variations in antioxidant and antihyperlipidemic properties of pomelo pulp (Citrus grandis [L.] Osbeck) in Thailand. Food Chem 2013, 139:735-743.

15. Sharma SD, Pandey BN, Mishra KP, Sivakami S: Amadori product and age formation during nonenzymatic glycosylation of bovine serum albumin in vitro. J Biochem Mol Biol Biophys 2002, 6:233-242.

16. Ardestani A, Yazdanparast R: Cyperus rotundus suppresses age formation and protein oxidation in a model of fructose-mediated protein glycoxidation. Int J Biol Macromol 2007, 41:572-578.

17. Bouma B, Kroon-Batenburg LM, Wu Y.P, Brünjes B, Posthuma G, Kranenburg O, de Groot PG, Voest EE, Gebbink MF: Glycation induces formation of amyloid cross- $\beta$ structure in albumin. J Biol Chem 2003, 278:41810-41819.

18. Meeprom A, Sompong W, Chan CB, Adisakwattana S: Isoferulic acid, a new anti-glycation agent, inhibits fructose- and glucose-mediated protein glycation in vitro. Molecules 2013, 18:6439-6454

19. Smith PR, Thornalley PJ: Mechanism of the degradation of non-enzymatically glycated proteins under physiological conditions. Eur J Biochem 1992, 210:729-739.

20. Nagai R, lkeda K, Higashi T, Sano H, Jinnouchi Y, Araki T, Horiuchi S: Hydroxyl radical mediates $\mathrm{N}^{\mathbf{\epsilon}}$-(Carboxymethyl) lysine formation from Amadori product. Biochem Biophys Res Commun 1997, 234:167-172.

21. Wu CH, Huang SM, Lin JA, Yen GC: Inhibition of advanced glycation endproduct formation by foodstuffs. Food Func 2011, 2:224-234.

22. Hinton D, Ames J: Site specificity of glycation and carboxymethylation of bovine serum albumin by fructose. Amino Acids 2006, 30:425-434.

23. Tappy L, Lê KA, Tran C, Paquot N: Fructose and metabolic diseases: new findings, new questions. Nutrition 2010, 26:1044-1049.

24. Schalkwijk CG, Stehouwer CD, van Hinsbergh VW: Fructose-mediated non-enzymatic glycation: sweet coupling or bad modification. Diabetes Metab Res Rev 2004, 20:369-382.

25. Sompong W, Meeprom A, Cheng H, Adisakwattana S: A comparative study of ferulic acid on different monosaccharide-mediated protein glycation and oxidative damage in bovine serum albumin. Molecule. 2013, 18:13886-13903.

26. Sakai M, Oimomi M, Kasuga M: Experimental studies on the role of fructose in the development of diabetic complications. Kobe J Med Sci 2002, 48:125-136.

27. Elosta A, Ghous T, Ahmed N: Natural products as anti-glycation agents: possible therapeutic potential for diabetic complications. Curr Diabetes Rev 2012, 8:92-108.

28. Wu CH, Yen GC: Inhibitory effect of naturally occurring flavonoids on the formation of advanced glycation endproducts. J Agric Food Chem 2005, 53:3167-3173.

29. Kusirisin W, Srichairatanakool S, Lerttrakarnnon P, Lailerd N, Suttajit M, Jaikang C, Chaiyasut C: Antioxidative activity, polyphenolic content and anti-glycation effect of some Thai medicinal plants traditionally used in diabetic patients. Med Chem 2009, 5:139-147.

30. Ho SC, Wu SP, Lin SM, Tang YL: Comparison of anti-glycation capacities of several herbal infusions with that of green tea. Food Chem 2010, 122:768-774.

31. Caengprasath N, Ngamukote S, Mäkynen K, Adisakwattana S: The protective effects of pomelo extract (Citrus Grandis L. Osbeck) against fructose-mediated protein oxidation and glycation. EXCLI J 2013, 12:491-502.

32. Marzban L, Verchere CB: The role of islet amyloid polypeptide in type 2 diabetes. Can J Diabetes 2004, 28:39-47.

33. Aćimović JM, Stanimirović BD, Mandić LM: The role of the thiol group in protein modification with methylglyoxal. J Serb Chem Soc 2009, 74:867-883. 
34. Dalle-Donne I, Giustarini D, Colombo R, Rossi R, Milzani A: Protein carbonylation in human diseases. Trend Mol Med 2003, 9:169-176.

35. Hung CY, Yen GC: Antioxidant activity of phenolic compounds isolated from Mesona procumbens Hemsl. J Agric Food Chem 2002, 50:2993-2997.

36. Lai LS, Chou ST, Chao WW: Studies on the antioxidative activities of Hsian-tsao (Mesona procumbens Hemsl) leaf gum. J Agric Food Chem 2001, 49:963-968.

37. Chusak C, Thilavech T, Adisakwattana S: Consumption of Mesona Chinensis Benth attenuates postprandial glucose and improves antioxidant status induced by a high carbohydrate meal in overweight subjects. Am J Chinese Med 2014, 42:315-336.

38. Cervantes-Laurean D, Schramm DD, Jacobson EL, Halaweish I, Bruckner GG, Boissonneault GA: Inhibition of advanced glycation end product formation on collagen by rutin and its metabolites. J Nutr Biochem 2006, $17: 531-540$

doi:10.1186/1472-6882-14-130

Cite this article as: Adisakwattana et al: Mesona Chinensis Benth extract prevents AGE formation and protein oxidation against fructose-induced protein glycation in vitro. BMC Complementary and Alternative Medicine 2014 14:130

\section{Submit your next manuscript to BioMed Central and take full advantage of:}

- Convenient online submission

- Thorough peer review

- No space constraints or color figure charges

- Immediate publication on acceptance

- Inclusion in PubMed, CAS, Scopus and Google Scholar

- Research which is freely available for redistribution 